\title{
Is a harsh childhood growth environment reflected in parental images and emotional distress in adulthood?
}

\author{
Annukka A. I. Kiviniemi ${ }^{1,2} \cdot$ Heli-Tuulie J. Koivumaa-Honkanen ${ }^{2,3,4} \cdot$ Hanna P. Heikkinen $^{5} \cdot$ Irma K. Moilanen $^{1,2}$ • \\ Hanna E. Ebeling ${ }^{1,2}$
}

Published online: 20 April 2020

(C) The Author(s) 2020

\begin{abstract}
Harsh parenting can predispose a child to emotional distress, whereas a supportive childhood environment furthers later subjective well-being. We investigated whether the mother's self-reported assessment of her strictness and the adult offspring's recollections of the disciplinary methods of their parents are reflected in the adult offspring's recalled parental images and current emotional distress, anxiety and depression as assessed by the Hopkins Symptom Check List (HSCL-25). Further, we investigated whether the offspring's parental images were also associated with the HSCL-25 scores. Data was collected from northern Finland. The mothers responded to a questionnaire when their child was seven years old $(N=354)$ and the adult offspring responded at age 28-29 $(N=337)$. The mother's assessment of her own strictness was associated both with the adult offspring's dominating images of their parents and their current emotional distress, anxiety and depression. The offspring's recollections of restriction and corporal punishment were associated with dominating parental images, and these images further with current emotional distress, anxiety and depression of the offspring. Correspondingly, the offspring's recollections of parental dialogic discipline were associated with supportive and sociable parental images, and recalled paternal dialogic discipline was associated with lower current emotional distress, particularly in the female offspring. In conclusion, harsh parenting was associated with dominating parental images, which in turn were associated with emotional distress in adulthood. Dialogic discipline and the father's role in parenting were emphasized in the offspring's well-being, but more research is needed to assess the importance of paternity for the offspring's subjective well-being.
\end{abstract}

Keywords Parent-child relationship $\cdot$ Parental images $\cdot$ Physical/corporal punishment $\cdot$ Parental strictness $\cdot$ Emotional distress/ anxiety/depression

\section{Introduction}

Adverse childhood experiences and early interpersonal difficulties have been linked with emotional distress in adulthood

Annukka A. I. Kiviniemi annukka.kiviniemi@pp.inet.fi

1 PEDEGO Research Unit, Clinic of Child Psychiatry, Faculty of Medicine, University of Oulu, Oulu, Finland

2 Clinic of Child Psychiatry, Oulu University Hospital, Oulu, Finland

3 Institute of Clinical Medicine, Department of Psychiatry, University of Eastern Finland, Kuopio, Finland

4 Department of Psychiatry, University Hospital of Kuopio, Kuopio, Finland

5 Department of Mathematical Sciences, University of Oulu, Oulu, Finland
(Oshio et al. 2013), and serious family dysfunction - such as domestic violence - with subsequent mental and somatic problems (Arnow 2004). Several studies have also found specific associations between childhood physical punishment such as pushing, grabbing, shoving, slapping, hitting - and difficulties in later psychological, physical or social development (Afifi et al. 2012; Breen et al. 2015; Gershoff 2002; 2013; Osterman et al. 2014; 2018; Yaffe and Burg 2014). A meta-analysis by Ferguson (2013) indicated minor, but significant longitudinal relationships between corporal punishment and several negative long-term outcomes. In one Finnish cross-sectional study, frequent corporal punishment in childhood was associated with depression and other mental health problems during adulthood (Osterman et al. 2014). Although the adverse effects of physical punishment have led to legislation against corporal punishment in many countries, some researchers and professionals still disagree about the 
advantages of moderate corporal punishment as an effective method of education (Yaffe and Burg 2014).

The Global Initiative to End All Corporal Punishment of Children was launched in 2013 (Gershoff 2013), and by 2019, 53 countries had legally banned corporal punishment in all settings, including the home (Saunders 2019). In Finland, all kinds of physical punishment were criminalized already in 1983 (Finnish Law 1983) as the second nation in the world - Sweden being the first, in 1979 (Janson et al. 2011). Thus, physical punishment was common and part of the educational culture in Finland until 1983, but its acceptability has steadily declined since the introduction of the law (Osterman et al. 2018). In a survey in 1981, physical punishment was accepted by $44 \%$ of the respondents, at least in exceptional situations (Peltoniemi 1983), whereas in a study carried out in 2014, only $15 \%$ of the respondents agreed at least partly on the acceptability of physical punishment of children (Sariola 2014).

Children have regarded corporal punishment as the least fair disciplinary method compared with methods such as reasoning, house arrest and withdrawal of privileges (Vittrup and Holden 2010). In line with this, emotional atmosphere - as the child's experience - was the most important aspect in the growth environment according to one Finnish longitudinal study (from age 8 to 36) (Pulkkinen 1994; 1996). Parents setting adequate boundaries, encouraging, helping, advising and being interested in their child, could create a supportive growth environment. Taking into account a child's developmental needs enables secure attachment (Bowlby 1973; 1977), which has been linked with supportive parental images (Kiviniemi et al. 2011; Kiviniemi et al. 2016) and with adult well-being and mental health (Mikulincer and Shaver 2007).

According to Bowlby (1998; 1973), experience with the mother and father (or other primary caregivers) leads to expectations and beliefs ("inner working models") about the self, others, and relationships. In the present study, "parental images" refer to the inner representations of parents which are thought to begin to be formed at the same time as an infant's memory system begins to encode affective experiences of its earliest attachment interactions (Amini et al. 1996; Bowlby 1998; 1973; Waters et al. 2000).

Parents can also transfer their punitive values and attitudes to their offspring (Gershoff 2013; Kemme et al. 2014). A dominant and authoritarian environment with illogical emotional responses (Pulkkinen 1994; 2002) predisposes children to insecure attachment (Bowlby 1984; Widom et al. 2018) and thus to an increased risk of depression in adulthood (Hankin et al. 2005). Lack of parental support during childhood is also associated with increased levels of depressive symptoms and chronic conditions (Shaw et al. 2004). Particularly, low maternal support could act as a risk factor for child depression (Harper et al. 2006). Furthermore, negative childhood experiences and lack of support can result in negative inner parental images, which can further predispose to adverse outcomes such as depression in young adults (Blatt et al. 1979).

Nevertheless, the environmental atmosphere of childhood can also modify the effects of physical punishment. Harper et al. (2006) found that parental support may serve as a buffer for children who are corporally punished. At low levels of paternal corporal punishment, maternal support moderated the effects of penalty (i.e., children were less depressed), but abundant paternal punishment was disadvantageous despite possible maternal support (Harper et al. 2006).

Although both predisposing and protective family factors have been investigated, the role of recalled comprehensive parental images has hitherto received only little attention, despite the fact that they are based on the parent-child interaction (Tazuke 2017) and may have a mediating effect on subsequent well-being. The aims of the present study were to investigate 1) whether the mother's self-reported assessment of her strictness (when the child was seven years old) and the adult offspring's recollections of childhood parental disciplinary methods, including corporal punishment, are reflected in the adult offspring's recalled parental images and their current emotional distress, anxiety and depression as assessed by the Hopkins Symptom Check List (HSCL-25); and 2) whether the adult offspring's parental images are associated with HSCL25.

\section{Method}

\section{Participants}

This sub-study of a longitudinal study, "The Mother-Child Follow-up Study 1971-1972," was conducted in northern Finland by the Clinic of Child Psychiatry at Oulu University Hospital and the University of Oulu. Figure 1 presents the flow-chart for the study sample, its participants and three phases. In the first phase, the study participants consisted of 491 women who gave birth to their healthy first or second child ( $N=495$, including four twin pairs) during 1971-1972 in Oulu University Hospital. Of these mothers, 310 were primiparous and 181 biparous (mean age 22.2 and 25.6 years, respectively). The second study phase (i.e. the 1st follow-up) was conducted in 1978-1979, when 353 of the mothers returned posted questionnaires about their 354 children (age 7 yrs., one twin pair), including items on the parent's socioeconomic status (Seitamo et al. 1979; Seitamo and WaszHöckert 1981). In the third study phase (i.e. the 2nd followup), the sample consisted of the grown-up offspring born in 1971-1972. In 2000, they were sent questionnaires $(N=472)$, and a total of $337(68.1 \%)$ of the $28-29$ years old offspring responded.

The present study represents the second and third study phases (including data of 251 mother-child pairs in both 
Fig. 1 Flowchart of the study population.

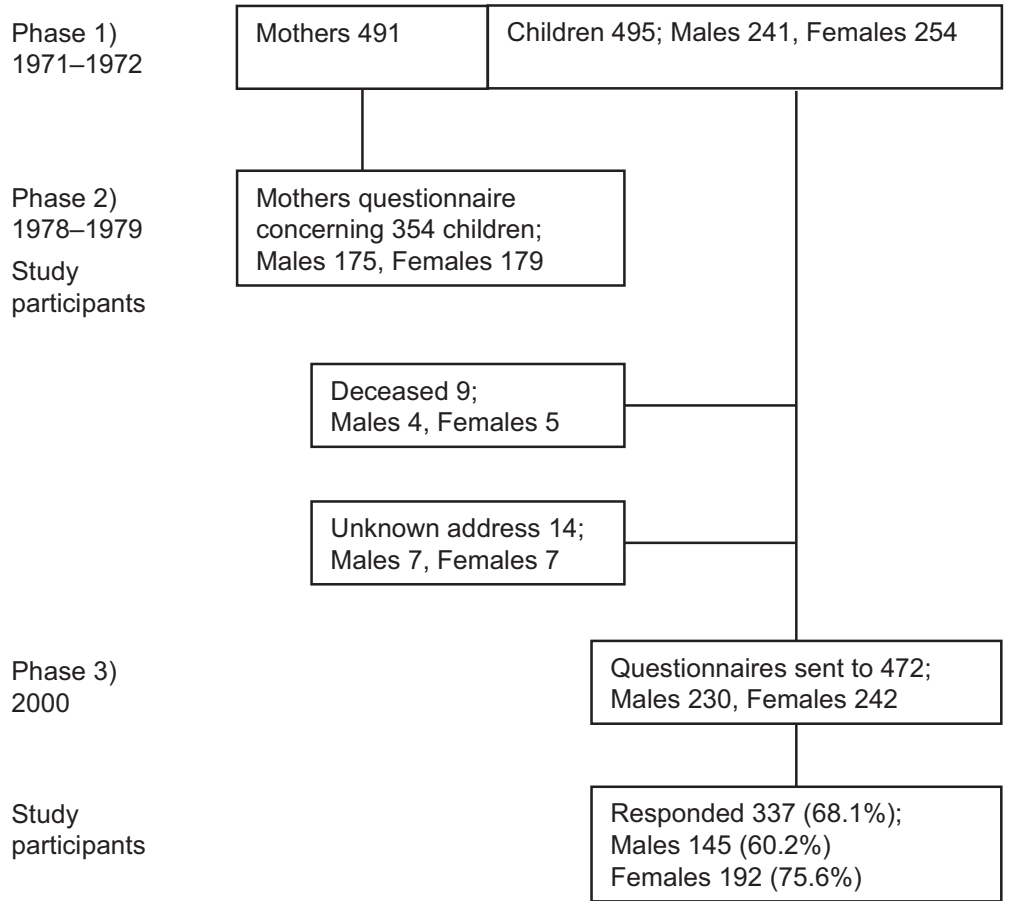

phases). At the child's age of seven, $91.9 \%$ of the mothers were married or cohabiting with the father of the child. Parents belonged most often to the middle social class (47.4\% of the mothers and $61.2 \%$ of the fathers), and correspondingly $18.8 \%$ and $23.4 \%$ to the higher and $33.8 \%$ and $15.4 \%$ to the lower social classes (Rauhala 1966). Threequarters $(75.1 \%)$ of the adult offspring were married or cohabiting, $47.1 \%$ had university, polytechnic or college level education and $57.9 \%$ were working full-time (Table 1).

\section{Procedure}

In Fig. 1, in the first study phase (1971-1972), the mothers responded to questionnaires after giving birth in Oulu University Hospital. They reported their current marital status, family income and the education of both parents. The data of the present study originated from the second study phase (1978-1979), when mothers responded to posted questionnaires. At that time, the child was aged seven and the mother was asked to assess her own disciplinary strictness. The other main study variables of the present study originated from the third study phase (2000), in which the adult offspring responded to posted questionnaires. These questionnaires included items on the adult offsprings' recalled childhood parental disciplinary methods, traits of the comprehensive images of their childhood parents and questions concerning possible current emotional distress. Address information was obtained from the National Population Register Centre. Nine of the offspring had died and 14 could not be traced.

\section{Measures}

The questionnaire at the child's age of seven years (phase 2)

At the child's age of seven, each mother was asked to evaluate her own parental disciplinary style (7 items); indicating whether she punishes in any way, uses spanking, scolds/criticizes, threatens, uses force, gets angry, or is harsh. A fivelevel Likert scale was used (never $=1$, seldom $=2$, sometimes $=3$, fairly often $=4$, often $=5$ ). Sum scores for maternal strictness were calculated as the means of item scores. The Cronbach's alpha value for maternal strictness was 0.78 .

\section{The questionnaire at the offspring's age of 28-29 years (phase 3)}

The offspring reported their recollections of both maternal and paternal disciplinary methods. Four different choices were given; dialogic discipline (i.e. discussion, reasoning), loss of privileges, house arrest and corporal punishment (all with alternatives $n o=0$, yes $=1$ ). Subsequently, "loss of privileges" and "house arrest" were combined into a new variable named 
Table 1 Characteristics of the parents at child's age seven and of the adult offspring at age $28-29$

Parents

Marital status (mother) $N=345$

Married or cohabiting

Other

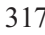

28

Social status /Socio-economic status

Mother $N=340$

\begin{tabular}{|c|c|c|}
\hline High & 64 & 18.8 \\
\hline Middle & 161 & 47.4 \\
\hline Low & 115 & 33.8 \\
\hline \multicolumn{3}{|l|}{ Father $N=338$} \\
\hline High & 79 & 23.4 \\
\hline Middle & 207 & 61.2 \\
\hline Low & 52 & 15.4 \\
\hline \multicolumn{3}{|l|}{ Adult offspring $N=337$} \\
\hline \multicolumn{3}{|l|}{ Marital status } \\
\hline Married & 121 & 35.9 \\
\hline Cohabiting & 132 & 39.2 \\
\hline Unmarried & 77 & 22.8 \\
\hline Separated/divorced & 5 & 1.5 \\
\hline Widowed & 1 & 0.3 \\
\hline Unknown & 1 & 0.3 \\
\hline \multicolumn{3}{|l|}{ Education } \\
\hline University & 53 & 16.0 \\
\hline Polytechnic & 26 & 7.8 \\
\hline College level & 77 & 23.3 \\
\hline Secondary & 96 & 29.0 \\
\hline Incomplete & 51 & 15.4 \\
\hline No vocational educ. & 28 & 8.5 \\
\hline Missing data ${ }^{\mathrm{a}}$ & 6 & \\
\hline \multicolumn{3}{|l|}{ Work situation } \\
\hline Working full-time & 194 & 57.9 \\
\hline Working part-time & 12 & 3.6 \\
\hline Self-employed/ entrepreneur & 20 & 6.0 \\
\hline Student & 29 & 8.7 \\
\hline Maternity/paternity leave & 44 & 13.1 \\
\hline Unemployed/laid-off & 28 & 8.3 \\
\hline Retired & 2 & 0.6 \\
\hline Other & 6 & 1.8 \\
\hline Missing data ${ }^{a}$ & 2 & \\
\hline
\end{tabular}

${ }^{\text {a }}$ A few participants did not answer every question

"restriction punishment" (neither of them $=0$, either or both of them $=1$ ). Each of these three disciplinary methods was investigated separately, and the absence of each form of discipline was used as a reference category.

The offspring's comprehensive parental images were assessed with the question, "How did you experience your childhood father/mother?" Altogether 17 different items were analyzed with a five-level Likert scale (never $=1$, seldom $=2$, sometimes $=3$, fairly often $=4$, very often $=5$ ). From these items, three image subscales were formed (c.f. Methods) (Tables 5 and 6 in "Appendix"). The first was supportive image (5 items); supporting hobbies, supporting schoolwork, giving positive feedback, arranging pleasant surprises and warmth/tenderness. The second was dominating image (6 items); demandingness, punishment, authoritativeness, possible violence, coldness/insensitivity and incoherency. The third was social image (3 items); talkativeness, happiness and spontaneity. The sum score for each image was calculated as the means of its item scores. The Cronbach's alphas for the three maternal images, i.e. supportive, dominating and social were $0.86,0.78$ and 0.64 , and correspondingly for the paternal images $0.85,0.76$ and 0.74 (Kiviniemi et al. 2011).

The supportive image of the present study resembles the Emotional Warmth subscale (EW) of the short version (sEMBU) (Arrindell et al. 1999; Arrindell et al. 2005) of the originally Swedish Egna Minnen Beträffanden Uppforstran subscale (EMBU) (Perris et al. 1980). Five of the six themes of the EW-subscale in the s-EMBU were included in our supportive image. Correspondingly, five of the seven themes of the Rejection subscale $(\mathrm{R})$ of the s-EMBU were included in our dominating image. The s-EMBU has been validated and used in different cultures (Arrindell et al. 1999; Arrindell et al. 2005). Since social abilities and personality of parents have been found to be associated with positive parenting outcomes (Prinzie et al. 2009), we also examined the recollection of sociable parental images.

The self-reported Hopkins Symptom Check List (HSCL25) was used to measure the current emotional distress, anxiety and depression symptoms of the adult offspring (Derogatis et al. 1973). The HSCL anxiety subscale includes 10 items; suddenly scared for no reason, feeling fearful, faintness/dizziness or weakness, nervousness or shakiness inside, heart pounding or racing, trembling, feeling tense or keyed up, headaches, spells of terror or panic, and feeling restless, inability to sit still. The HSCL depression subscale has 13 items; feeling low in energy/slowed down, blaming oneself for things, crying easily, loss of sexual interest or pleasure, feeling hopeless about the future, feeling blue, feeling lonely, thoughts of ending one's life, feeling of being trapped or caught, worrying too much about things, feeling no interest in things, feeling everything is an effort, and feelings of worthlessness. HSCL-25 also includes two additional questions, i.e. poor appetite and difficulty in falling/staying asleep, which were used when calculating the HSCL-25 total score (Veijola et al. 2003; Winokur et al. 1984). Each of these items had four response alternatives ( not at all $=1$, a little $=2$, quite $a$ bit $=3$, extremely $=4$ ). The mean scores were computed for the HSCL-25 total score as well as for its anxiety and depression subscales. A mean score of $\geq 1.55$ has usually been used 
as the threshold for inclusion, but $\geq 1.75$ has also been used (Finne et al. 2014; Finne et al. 2016; Sandanger et al. 1998; Veijola et al. 2003). We used continuous scores in the analyses, but we also give basic statistics with a screening cut-off point at $\geq 1.55$.

\section{Data analyses}

The IBM SPSS 24 statistical package was used for statistical analysis (IBM SPSS Statistics for Macintosh, Version 24.0). Principal Component Analysis (PCA) with Varimax rotation had previously been used to construct the parental images (Kiviniemi et al. 2016). Mean scores for men and women were compared by independent samples $T$-tests. A multivariate general linear model (GLM) was used to investigate the relationships between maternal strictness assessed by the childhood mother, the adult offspring's recollections of parental disciplinary methods, their assessments of their parental images and their current emotional distress (HSCL-25).

In each GLM model, women were the reference category and interactions between gender and other explanatory variables were investigated. In Model 1, the associations between maternal strictness assessed by the childhood mother, the adult offspring's recalled childhood parental disciplinary methods and their parental images were studied (Table 2). In Model 2, the relationships between maternal strictness assessed by the childhood mother, the adult offspring's recalled childhood parental disciplinary methods and their current emotional distress (HSCL-25) were investigated (Table 3). In Model 3, the relationship between the adult offspring's comprehensive parental images, both maternal and paternal, and their current emotional distress (HSCL-25) was studied (Table 4). Adjustment by sociodemographic variables, i.e. the parent's socio-economic and marital status and the adult offspring's marital status, education and work situation, was not made, because these variables had no statistically significant correlations either with dependent variables of the models or with other effects of the models. The assumptions of the models were explored and confirmed.

\section{Results}

The mean score of the mother's self-reported strictness $(M=2.18, S D=0.48, N=332)$ was composed most often of scolding and criticizing item scores $(M=2.74$, $S D=0.74)$, followed by getting angry $(M=2.73, S D=$ $0.72)$, punishing in any way $(M=2.43, S D=0.68)$, being harsh $(M=2.26, S D=0.73)$, using force $(M=1.94, S D=$ $0.80)$, threatening $(M=1.80, S D=0.85)$, and most rarely of spanking scores $(M=1.39, S D=0.6)$.

The offspring reported that in their childhood the majority of parents had used dialogic disciplinary methods i.e. discussion and reasoning (mothers $90.6 \%$; fathers $75.2 \%$ ). More than half of the parents had used restriction punishment (mothers $65.4 \%$; fathers $59.1 \%$ ) and more than a quarter corporal punishment (mothers $25.7 \%$; fathers $38.6 \%$ ).

The offspring's maternal and paternal images were most often sociable (maternal $M=3.83, S D=0.73$; paternal $M=3.33, S D=0.81$ ), then supportive (maternal $M=3.48$, $S D=0.77$; paternal $M=3.12, S D=0.82)$ and least often dominating (maternal $M=2.33, S D=0.62$; paternal $M=2.47, S D=0.67)$.

About $13-18 \%$ of the adult offspring reported having current emotional distress; $17.4 \%$ of them scored above the screening cut-off point $(\geq 1.55)$ on the HSCL-25 total scale, $12.6 \%$ on the HSCL anxiety subscale and $18.3 \%$ on the HSCL depression subscale. Women scored higher than men on the HSCL-25 total scale $(M=1.36, S D=0.3$ vs. $M=1.28, S D=0.25 ; p=.008)$ and on the HSCL depression subscale $(M=1.40, S D=0.37$ vs. $M=1.29$, $S D=0.29 ; p=.002)$.

\section{The mother's self-reported strictness and the adult offspring's parental images}

Maternal strictness assessed by the childhood mother was positively associated with the adult offspring's dominating maternal $(p=.005)$ and paternal images $(p=.022)$ and negatively with a sociable maternal $(p=.022)$ image, but not with the supportive parental images (Table 2, Model 1).

\section{Adult offspring's recollection of parental disciplinary methods and parental images}

In Model 1, the dialogic discipline method of each parent was positively associated with corresponding supportive (mother $p<.001$; father $p<.001$ ) and sociable parental images (mother $p=.002$; father $p<.001$ ), and negatively with a dominating parental image (mother $p=.002$; father $p=.001$ ) (Table 2). The adult offspring's recollection of restriction punishment was positively associated with a corresponding dominating parental image (mother $p=.001$; father $p=.006$ ), and when used by the mother negatively with supportive $(p=.011)$ and sociable $(p=.004)$ maternal images. Recalled restriction punishment used by the father was positively associated with a supportive maternal image ( $p=.012)$, but no such connection was found between recalled restriction punishment used by the mother and a supportive paternal image. If either parent was recalled as having used corporal punishment, the image of the corresponding parent was on average more dominating (mother $p=.028$; father $p<.001$ ), but maternal corporal punishment was also positively 


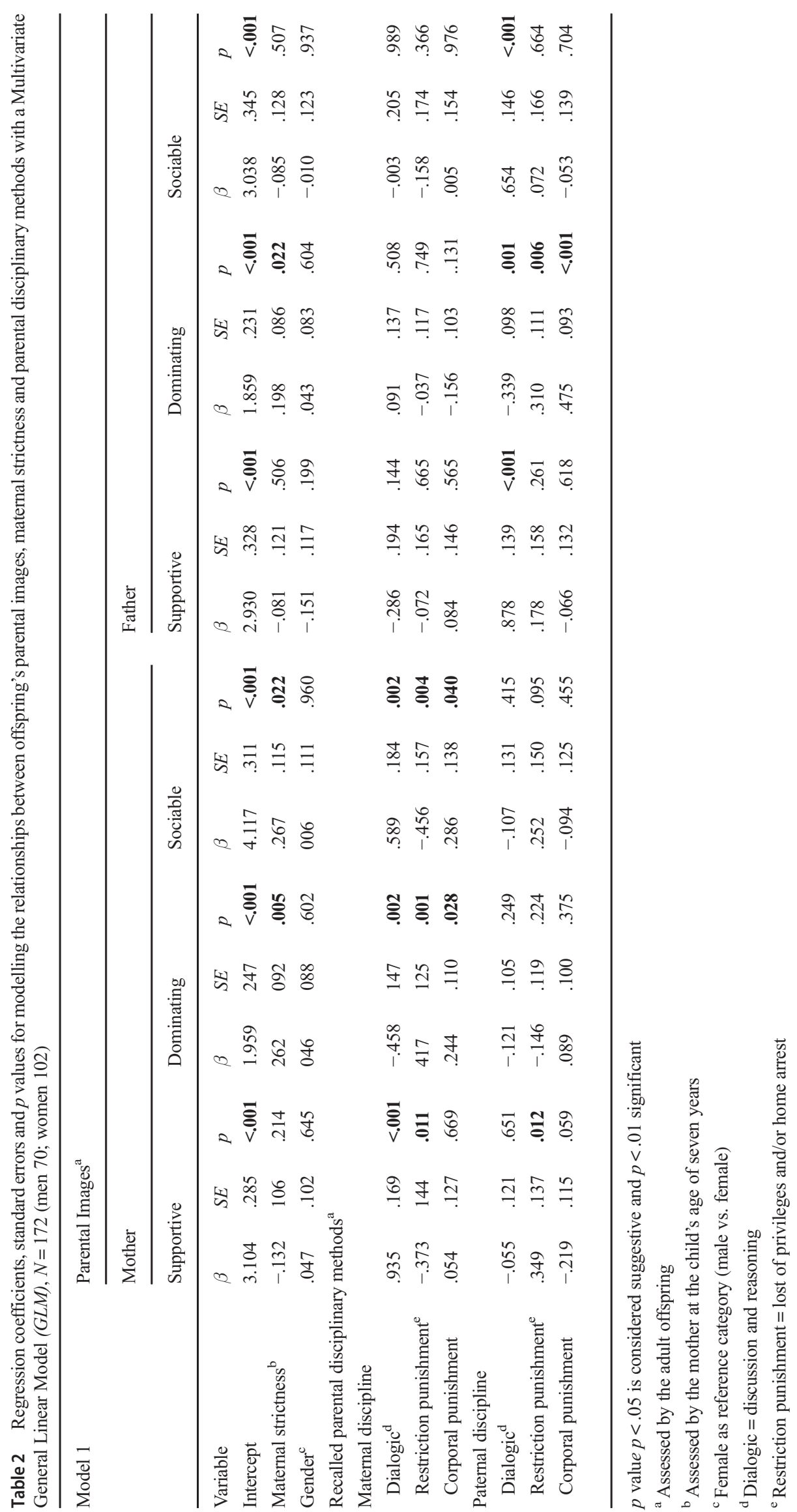


Table 3 Regression coefficients, standard errors and $p$ values for modelling relationships between offspring's current emotional distress (HSCL-25), maternal strictness and parental disciplinary methods with a Multivariate General Linear Model (GLM), $N=189$ (men 76; women 113)

\begin{tabular}{|c|c|c|c|c|c|c|c|c|c|c|}
\hline \multirow{2}{*}{$\begin{array}{l}\text { Model } 2 \\
\text { Variable }\end{array}$} & \multirow[t]{2}{*}{$n=$ Not $\mid$ Yes } & \multicolumn{3}{|c|}{ HSCL $-25^{\mathrm{a}}$} & \multicolumn{3}{|c|}{ Anxiety- $10^{\mathrm{a}}$} & \multicolumn{3}{|c|}{ Depression- $-13^{\mathrm{a}}$} \\
\hline & & $\beta$ & $S E$ & $p$ & $\beta$ & $S E$ & $p$ & $\beta$ & $S E$ & $p$ \\
\hline Intercept & & 1.220 & .109 & $<.001$ & 1.129 & .104 & $<.001$ & 1.295 & .132 & $<.001$ \\
\hline Maternal strictness ${ }^{\mathrm{b}}$ & & .125 & .041 & .003 & .117 & .039 & .003 & .133 & .050 & .008 \\
\hline Gender $^{\mathrm{c}}$ & & -.226 & .077 & .004 & -.114 & .073 & .118 & -.342 & .092 & $<.001$ \\
\hline \multicolumn{11}{|c|}{ Recalled parental disciplinary methods ${ }^{\mathrm{a}}$} \\
\hline \multicolumn{11}{|c|}{ Maternal discipline } \\
\hline Dialogic $^{\mathrm{d}}$ & $23 \mid 166$ & .050 & .064 & .432 & .052 & .061 & .397 & .057 & .077 & .465 \\
\hline Restriction punishment $\mathrm{e}^{\mathrm{e}}$ & $63 \mid 126$ & .037 & .055 & .507 & .025 & .053 & .628 & .036 & .067 & .590 \\
\hline Corporal punishment & $143 \mid 46$ & -.067 & .049 & .171 & -.044 & .046 & .340 & -.096 & .059 & .106 \\
\hline \multicolumn{11}{|l|}{ Paternal discipline } \\
\hline Dialogic $^{\mathrm{d}}$ & $58 \mid 131$ & -.290 & .056 & $<.001$ & -.189 & .053 & $<.001$ & -.376 & .067 & $<.001$ \\
\hline Dialogic $^{d} \times$ Gender $^{c}$ & & .182 & .089 & .042 & .066 & .084 & .431 & .282 & .107 & .009 \\
\hline Restriction punishment $^{\mathrm{e}}$ & $80 \mid 109$ & .001 & .053 & .990 & -.017 & .050 & .733 & .031 & .063 & .624 \\
\hline Corporal punishment & 127 | 62 & .038 & .045 & .399 & .031 & .043 & .462 & .027 & .054 & .621 \\
\hline
\end{tabular}

Note Hopkins Symptom Checklist-25 (HSCL-25) and its anxiety (Anxiety-10) and depression (Depression-13) subscales; $p$ value $p<.05$ is considered suggestive and $p<.01$ significant

${ }^{\text {a }}$ Assessed by the adult offspring

${ }^{\mathrm{b}}$ Assessed by the mother at the child's age seven years

${ }^{\mathrm{c}}$ Female as reference category (male vs. female)

${ }^{\mathrm{d}}$ Dialogic $=$ discussion and reasoning

${ }^{\mathrm{e}}$ Restriction punishment $=$ lost of privileges and/or home arrest

associated with a sociable maternal image $(p=.040)$.

Gender of the offspring had no independent effect on the parental images or their relationship with recalled parental discipline methods.

Table 4 Regression coefficients, standard errors and $p$ values for modelling relationship between offspring's current emotional distress (HSCL-25) and parental images with a Multivariate General Linear Model (GLM), N=297 (men 132; women 165)

\begin{tabular}{|c|c|c|c|c|c|c|c|c|c|}
\hline \multirow{2}{*}{$\begin{array}{l}\text { Model } 3 \\
\text { Variable }\end{array}$} & \multicolumn{3}{|c|}{$\mathrm{HSCL}-25^{\mathrm{a}}$} & \multicolumn{3}{|c|}{ Anxiety- $10^{\mathrm{a}}$} & \multicolumn{3}{|c|}{ Depression- $13^{\mathrm{a}}$} \\
\hline & $\beta$ & $S E$ & $p$ & $\beta$ & $S E$ & $p$ & $\beta$ & $S E$ & $p$ \\
\hline Intercept & 1.086 & .143 & $<.001$ & 1.067 & .143 & $<.001$ & 1.071 & .175 & $<.001$ \\
\hline Gender $^{\mathrm{b}}$ & -.106 & .029 & $<.001$ & -.085 & .029 & .003 & -.140 & .035 & $<.001$ \\
\hline \multicolumn{10}{|c|}{ Parental images $^{\mathrm{a}}$} \\
\hline \multicolumn{10}{|c|}{ Mother } \\
\hline Supportive & .027 & .027 & .321 & .020 & .027 & .470 & .037 & .033 & .264 \\
\hline Dominating & .077 & .027 & .005 & .055 & .027 & .047 & .090 & .033 & .008 \\
\hline Sociable & -.017 & .023 & .456 & -.017 & .023 & .447 & -.017 & .028 & .537 \\
\hline \multicolumn{10}{|l|}{ Father } \\
\hline Supportive & .004 & .025 & .867 & .016 & .025 & .504 & -.010 & .030 & .729 \\
\hline Dominating & .090 & .023 & $<.001$ & .072 & .023 & .002 & .108 & .028 & $<.001$ \\
\hline Sociable & -.049 & .022 & .025 & -.032 & .022 & .147 & -.052 & .027 & .052 \\
\hline
\end{tabular}

Note Hopkins Symptom Checklist-25 (HSCL-25) and its anxiety (Anxiety-10) and depression (Depression-13) subscales; $p$ value $p<.05$ is considered suggestive and $p<.01$ significant

${ }^{a}$ Assessed by the adult offspring

${ }^{\mathrm{b}}$ Female as reference category (male vs. female) 
Table 5 Loadings of maternal variables for each image component in principal component analysis (PCA) with the varimax rotation method and Kaiser normalization

\begin{tabular}{|c|c|c|c|c|c|}
\hline & \multicolumn{4}{|l|}{ Components } & \\
\hline & Supportive & Dominating & Sociable & $\begin{array}{l}\text { Hard- } \\
\text { working }\end{array}$ & \\
\hline$\%$ of Variance (total $59.9 \%$ ) & 22.3 & 15.8 & 14.3 & 7.6 & \\
\hline Eigenvalue & 5.64 & 2.05 & 1.31 & 1.19 & \\
\hline Cronbach's Alpha & 0.857 & 0.78 & 0.641 & $0.361^{\mathrm{b}}$ & Communalities \\
\hline Mother image variables & $n=335$ & $n=328$ & $n=326$ & $n=334$ & \\
\hline Supported, took part in hobbies & 0.813 & -0.062 & 0.123 & 0.086 & 0.688 \\
\hline Supported with school work & 0.801 & -0.088 & 0.191 & 0.095 & 0.696 \\
\hline Gave acknowledgement, praise & 0.760 & -0.135 & 0.290 & -0.007 & 0.680 \\
\hline Arranged pleasant surprises & 0.704 & 0.016 & 0.005 & -0.052 & 0.498 \\
\hline Warm, tender & 0.680 & -0.229 & 0.388 & 0.004 & 0.665 \\
\hline Demanding & 0.144 & 0.806 & 0.026 & 0.131 & 0.687 \\
\hline Punished & -0.052 & 0.760 & -0.126 & -0.148 & 0.618 \\
\hline Authoritative & -0.166 & 0.741 & 0.029 & 0.126 & 0.593 \\
\hline Hit when angry, was violent & -0.388 & 0.521 & -0.067 & -0.160 & 0.453 \\
\hline Cold, insensitive & -0.450 & 0.510 & -0.437 & 0.128 & 0.670 \\
\hline Incoherent, erratic and unpredictable & -0.454 & 0.462 & -0.219 & -0.029 & 0.468 \\
\hline Talkative & 0.160 & 0.043 & 0.765 & 0.030 & 0.614 \\
\hline Happy & 0.444 & -0.238 & 0.672 & -0.013 & 0.705 \\
\hline Spontaneous in relationships & 0.034 & 0.011 & 0.656 & 0.003 & 0.432 \\
\hline Domestic $^{\mathrm{a}}$ & 0.146 & -0.104 & 0.522 & 0.091 & $0.313^{\mathrm{a}}$ \\
\hline Committed to work & -0.108 & 0.075 & -0.101 & 0.852 & 0.754 \\
\hline Diligent & 0.278 & -0.056 & 0.364 & 0.660 & 0.648 \\
\hline
\end{tabular}

Loadings of variables to form each component are indicated in bold

${ }^{a}$ Excluded from the component because of low communality

${ }^{\mathrm{b}}$ Hard-working not included in this study

\section{The mother's self-reported assessment of her strictness and the adult offspring's current emotional distress}

Maternal strictness was associated with the adult offspring's higher HSCL-25 total and subscale scores (total $p=.003$; anxiety $p=.003$; depression $p=.008$ ) (Table 3, Model 2).

\section{Adult offspring's recollection of parental disciplinary methods and current emotional distress}

The recalled paternal dialogic disciplinary method (discussion, reasoning) was associated with lower HSCL-25 total and subscale scores (all $p<.001$ ), whereas neither restriction nor corporal punishment were associated with current emotional distress (Table 3, Model 2). These correlations were moderated by gender. In women, paternal dialogic discipline was associated with decreased HSCL-25 total and depression subscale scores more clearly than in men $(p=.042, p=.009$ for interaction).

\section{Adult offspring's parental images and current emotional distress}

Both maternal and paternal dominating images were associated with higher emotional distress, i.e. with higher HSCL-25 total scores (maternal $p=.005$; paternal $p<.001$ ), anxiety subscale scores $(p=.047 ; p=.002)$ and depression subscale scores $(p=.008 ; p<.001)$ (Table 4, Model 3). A sociable paternal image was associated with lower HSCL-25 total score $(p=.025)$, whereas neither maternal nor paternal supportive images were statistically significantly associated with current emotional distress. Gender had an independent effect on the emotional distress; men had lower HSCL-scores (total $p<.001$; anxiety $p=.003$; depression $p<.001)$. 
Table 6 Loadings of paternal variables for each image component in principal component analysis (PCA) with the varimax rotation method and Kaiser normalization

\begin{tabular}{|c|c|c|c|c|c|}
\hline & \multicolumn{4}{|l|}{ Components } & \\
\hline & Supportive & Dominating & Sociable & $\begin{array}{l}\text { Hard- } \\
\text { working }\end{array}$ & \\
\hline$\%$ of Variance (total $61.1 \%$ ) & 20.9 & 16.9 & 13.5 & 9.9 & \\
\hline Eigenvalue & 5.25 & 2.37 & 1.58 & 1.19 & \\
\hline Cronbach's Alpha & 0.852 & 0.764 & 0.735 & 0.598 & Communalities \\
\hline Father image variables & $n=319$ & $n=319$ & $n=315$ & $n=321$ & \\
\hline Supported, took part in hobbies & 0.818 & 0.011 & 0.095 & -0.022 & 0.679 \\
\hline Supported with school work & 0.843 & -0.066 & 0.091 & 0.115 & 0.737 \\
\hline Gave acknowledgement, praise & 0.814 & -0.112 & 0.237 & -0.021 & 0.732 \\
\hline Arranged pleasant surprises & 0.620 & -0.060 & 0.289 & 0.061 & 0.476 \\
\hline Warm, tender & 0.603 & -0.242 & 0.433 & -0.035 & 0.611 \\
\hline Demanding & 0.191 & 0.657 & 0.009 & 0.326 & 0.574 \\
\hline Punished & -0.006 & 0.736 & -0.036 & -0.005 & 0.543 \\
\hline Authoritative & -0.077 & 0.743 & -0.059 & 0.331 & 0.671 \\
\hline Hit when angry, was violent & -0.185 & 0.650 & 0.012 & -0.332 & 0.568 \\
\hline Cold, insensitive & -0.426 & 0.540 & -0.378 & -0.091 & 0.625 \\
\hline Incoherent, erratic and unpredictable & -0.292 & 0.623 & -0.118 & -0.215 & 0.534 \\
\hline Talkative & 0.262 & 0.018 & 0.817 & -0.008 & 0.736 \\
\hline Happy & 0.394 & -0.228 & 0.739 & 0.053 & 0.756 \\
\hline Spontaneous in relationships & 0.099 & 0.037 & 0.733 & 0.064 & 0.553 \\
\hline Domestic $^{\mathrm{a}}$ & $0.301^{\mathrm{a}}$ & -0.281 & 0.149 & 0.008 & $0.192^{\mathrm{a}}$ \\
\hline Committed to work & -0.186 & 0.152 & 0.092 & 0.774 & 0.665 \\
\hline Diligent & 0.225 & -0.125 & 0.007 & 0.820 & 0.738 \\
\hline
\end{tabular}

Loadings of variables to form each component are indicated in bold

${ }^{\text {a }}$ Excluded from component because of low communality

${ }^{\mathrm{b}}$ Hard-working not included in this study

\section{Discussion}

The purpose of the study was to determine whether the recollections of parental disciplinary methods (e.g. corporal punishment, restriction punishment or dialogic discipline), are reflected either in the adult offspring's recalled parental images or in their current emotional distress, anxiety and depression, and whether these two outcomes are related. Thus far, previous literature has shown that harsh parenting can predispose an offspring to emotional distress (Afifi et al. 2012; Breen et al. 2015), whereas a supportive childhood environment may promote the offspring's later subjective well-being (Kiviniemi et al. 2011; Kiviniemi et al. 2016). It is worth emphasizing that although parental images are based on the parent-child interaction, they have received only a little attention (Tazuke 2017). In the present study, parental images were assessed by the adult offspring with a total of 17 different items closely describing individual characteristics, from which three trait combinations (supportive, dominating, sociable) were formed. We proposed that these comprehensive items represented the internalized images of childhood parents and were present in the respondent's adult life.

One of our key findings was that recalled paternal dialogic discipline in childhood was associated with low levels of adult emotional distress, anxiety and depression. The positive link with respect to depression was stronger among women, but similar between the genders with respect to anxiety symptoms. Furthermore, the adult offspring's recollections of parental restriction and corporal punishment were reflected in their dominating parental images, which - in turn - were related to emotional distress, anxiety and depression. Neither recollected parental restriction nor corporal punishment were directly associated with emotional distress.

One of our aims was to investigate whether the mother's self-reported assessment of her own strictness is reflected in the offspring's recalled parental images. We found that the aspects of maternal strictness (assessed by the childhood mother herself), such as punishment, spanking, scolding, criticizing, threatening, using force, getting angry and being harsh, corresponded to the traits of offspring's dominating 
parental images such as demandingness, authoritativeness, coldness, insensitivity and unpredictability, in addition to possible punitive and violent tendencies. Thus, it is not surprising that maternal strictness was positively correlated with a dominating maternal image. However, we found that the mother's strictness also correlated with the father's dominating image, reflecting a comprehensive experience of a dominating family atmosphere.

We found further that the supportive parental images and recollections of dialogic discipline were associated. The former were described with high quality reciprocal interaction, such as supporting hobbies and schoolwork, giving positive feedback, arranging pleasant surprises as well as general parental warmth and tenderness. In general, these factors can support the offspring's subjective well-being via increasing active mastery of his or her own life (Leiman 2012; Stetsenko and Arievitch 2004). On the other hand, the offspring's recollections of parental restriction or corporal punishment were positively associated with a dominating image of the corresponding parent. Children are also known to have regarded corporal punishment as the least fair disciplinary method, compared with methods such as reasoning, house arrest and withdrawal of privileges. In the study of Vittrup and Holden (2010), the importance of a dialogue was expressed by one 8-year-old girl "You really need to talk to your child if they don't listen to you. You need to sit down and talk to them. If that doesn't work, take a privilege away. [Spanking] doesn't teach the kid a lesson".

Finland was the second nation where all corporal punishment was banned, including in the home. To date, over fifty countries have passed the same legality restrictions, but much work still remains to be done. According to Saunders (2019), corporal punishment of children should not be seen only as an infringement of their human rights but also as a disquieting public health concern. Although several previous researchers have come to the same conclusion as our study that corporal punishment does not have any favorable consequences, children's physical discipline continues to be tolerated in many countries, including many Western countries (Gershoff 2013; Saunders 2019).

A surprising result in the present study was that the adult offspring's recollection of corporal punishment used by the mother was positively associated with a sociable maternal image (including talkativeness, happiness and spontaneity). The data of our study was collected before and during wide societal changes affecting attitudes and practices in the use of corporal punishment (Osterman et al. 2018; Peltoniemi 1983; Sariola 2014). Among other things, Waters et al. (2000) emphasized that fluctuations in attachment security related to meaningful changes in the family environment may enable changes in attachment relations. Zhang and Labouvie-Vief (2004) also indicated that although attachment style is relatively stable on a short span (six-year period), it is characterized more by fluctuation than by stability. It is also possible that spontaneous, sociable mothers used corporal discipline when it was legally accepted but changed their practices when it was no longer legal. Thus, changing disciplinary practices and attachment security fluctuations may partly explain our findings between corporal punishment and a sociable maternal image.

The relationships between childhood events and adult wellbeing are complex. Protective factors such as parental support may moderate the effects of potential risk factors, and e.g. corporal punishment may indicate fairer sanction in a supportive atmosphere compared to circumstances with lack of such positive aspects (Harper et al. 2006). Thus, we investigated whether the offspring's recollections of childhood parental disciplinary methods or parental images correlated with their possible current emotional distress (HSCL-25), anxiety and depression.

Unlike in the study of Harper et al. (2006), in which high paternal support had a direct correlation with low levels of child's depression, in our study recalled paternal dialogic discipline, not his supportive image, was associated with a lower level of emotional distress, anxiety and depression - in the case of depression more clearly among the female offspring. One of our key findings was that paternal dialogic discipline may act as a protective factor for the offspring's well-being. Correspondingly, the adult offspring's dominating parental images - paternal statistically more clearly than maternal were associated with higher levels of adult emotional distress, but only the paternal social image was linked with lower levels of distress. These results are partly consistent with those of previous studies, in which parental support (Shaw et al. 2004) and a good parent-child relationship have been associated with reduced daily psychological distress (Mallers et al. 2010).

Research literature underscores the relationship between physical punishment in childhood and subsequent depression, anxiety and other adverse psychiatric symptoms (Afifi et al. 2013; Arnow 2004; Gershoff 2002; Oshio et al. 2013; Osterman et al. 2014). In the present study, we found that recalled harsh discipline, i.e. restriction and corporal punishment, even if not related to emotional distress, was related to dominating parental images, which in turn were related to emotional distress, anxiety and depression.

Although harsh parental discipline reported by the adult offspring - i.e. their recollection of restriction and corporal punishment - was not associated with the adult offspring's current well-being, maternal strictness assessed by the mother herself was reflected in the adult offspring's emotional distress, anxiety and depression. This latter result is consistent with those of an earlier study in which higher levels of maternal punishment increased the offspring's depression (Harper et al. 2006). In our study, it may well be that the mothers' reports were based on significant negative disciplinary events 
and atmosphere, and even if maternal strictness is not remembered by the offspring, it may have negative emotional effects. On the other hand, for the offspring it appeared that rather than remembering possible negative disciplinary practice, it was more important how they recalled their comprehensive parental images.

In a recent prospective study, childhood neglect and physical abuse were associated with a higher level of insecure attachment style in adulthood, which in turn was linked with higher levels of anxiety and depression and lower self-esteem (Widom et al. 2018). In our study, a dominating parental image included the negatively colored memories of the childhood parents, such as authoritativeness, coldness and insensitivity. We suggest that these factors are closely associated with insecure attachment patterns, which are linked with a dominating growth environment (incl. corporal punishment, domestic violence).

In the present study the recollection of positive childhood paternal dialogic discipline, such as discussion and reasoning, was related to adult emotional distress in a protective way. The results also indicate that overall dominating parental images may play a causative role between the harsher aspects of a childhood growth environment and later emotional distress. We suggest that parental dialogic discipline makes it possible to emotionally and cognitively distinguish different experiences and to master emotional distress, and thus that dialogic upbringing promotes well-being. On the other hand, children with experience of harsh parental discipline are prone to establish negative internal images of their parents. Without the possibility of consciously processing negative childhood memories, these internalizations may be a risk for later wellbeing. The present study also emphasizes the father's role in parenting. More research is needed concerning the importance of the father for the offspring's later well-being.

In conclusion, the present study supports arguments for banning corporal punishment in countries where this has not yet been done. It provides an alternative by encouraging parents to use discussion and reasoning instead of corporal punishment, since the memory images of one's parents have farreaching effects.

\section{Limitations}

The longitudinal setting of this study allowed us to strengthen and expand the views of two generations regarding the same growth environment. However, we had only the mothers' assessments of discipline at the child's age of seven, not the fathers'. Furthermore, the offsprings' current subjective wellbeing may have been reflected in their assessments of their own childhood. The general attitude related to the banning of corporal punishment may have affected the answers of the respondents. The attitudes between our research data collection points may have changed towards child-friendlier parenting. Thus, the results need to be interpreted with some caution in different societies with varying legislation. Further research is proposed in dissimilar cultural contexts.

Acknowledgements We are grateful to the Gyllenberg Foundation for grants to Hanna Ebeling and Annukka Kiviniemi, to the Northern Ostrobothnia Hospital District, the Finnish Cultural Foundation, the Psychological Institute of Finland, the Lisa Andström Foundation and the University of Oulu Scholarship Fund for grants to Annukka Kiviniemi. We are also grateful to Ole Wasz-Höckert $\dagger$ and Leila K. Seitamo, who implemented the first parts of this longitudinal study.

Funding Information Open access funding provided by University of Oulu including Oulu University Hospital.

\section{Compliance with Ethical Standards}

The Ethical Committee of the Northern Ostrobothnia Hospital District in Finland approved the study, and written permissions were obtained from the young adults.

Conflict of interest The authors report no conflicts of interest. The authors alone are responsible for the content and writing of the paper.

Open Access This article is licensed under a Creative Commons Attribution 4.0 International License, which permits use, sharing, adaptation, distribution and reproduction in any medium or format, as long as you give appropriate credit to the original author(s) and the source, provide a link to the Creative Commons licence, and indicate if changes were made. The images or other third party material in this article are included in the article's Creative Commons licence, unless indicated otherwise in a credit line to the material. If material is not included in the article's Creative Commons licence and your intended use is not permitted by statutory regulation or exceeds the permitted use, you will need to obtain permission directly from the copyright holder. To view a copy of this licence, visit http://creativecommons.org/licenses/by/4.0/.

\section{References}

Afifi, T. O., Mota, N. P., Dasiewicz, P., MacMillan, H. L., \& Sareen, J. (2012). Physical punishment and mental disorders: Results from a nationally representative US sample. Pediatrics, 130(2), 184-192. https://doi.org/10.1542/peds.2011-2947.

Afifi, T. O., Mota, N., MacMillan, H. L., \& Sareen, J. (2013). Harsh physical punishment in childhood and adult physical health. Pediatrics, 132(2), e333-e340. https://doi.org/10.1542/peds.20124021.

Amini, F., Lewis, T., Lannon, R., Louie, A., Baumbacher, G., McGuinness, T., \& Schiff, E. Z. (1996). Affect, attachment, memory: Contributions toward psychobiologic integration. Psychiatry, 59(3), 213-239.

Arnow, B. A. (2004). Relationships between childhood maltreatment, adult health and psychiatric outcomes, and medical utilization. The Journal of Clinical Psychiatry, 65(Suppl 12), 10 Retrieved from https://www.ncbi.nlm.nih.gov/pubmed/15315472.

Arrindell, W. A., Sanavio, E., Aguilar, G., Sica, C., Hatzichristou, C., Eisemann, M., \& Battagliese, G. (1999). The development of a short form of the EMBU: Its appraisal with students in Greece, Guatemala, Hungary and Italy. Personality and Individual 
Differences, 27(4), 613-628. https://doi.org/10.1016/S01918869(98)00192-5.

Arrindell, W. A., Akkerman, A., Bagés, N., Feldman, L., Caballo, V. E., Oei, T. P., \& Montgomery, I. (2005). The short-EMBU in Australia, Spain, and Venezuela. European Journal of Psychological Assessment, 21(1), 56-66. https://doi.org/10.1027/1015-5759.21.1. 56.

Blatt, S. J., Wein, S. J., Chevron, E. S., \& Quinlan, D. M. (1979). Parental representations and depression in normal young adults. Journal of Abnormal Psychology, 88(4), 388-397. https://doi.org/10.1037/ 0021-843X.88.4.388.

Bowlby, J. (1973). Attachment and loss. vol. 2, Separation: Anxiety and anger. New York.: Basic Books Retrieved from https://oula.finna.fi/ Record/oula.1555305.

Bowlby, J. (1977). The making and breaking of affectional bonds. I. Aetiology and psychopathology in the light of attachment theory. The British Journal of Psychiatry, 130(3), 201-210.

Bowlby, J. (1984). Violence in the family as a disorder of the attachment and caregiving systems. American Journal of Psychoanalysis, 44(1), 9-27.

Bowlby, J. (1998). Attachment and loss. volume 3, Loss: Sadness and depression (Pimlico ed ed.). London: Pimlico. Retrieved from https://oula.finna.fi/Record/oula.1555309.

Breen, A., Daniels, K., \& Tomlinson, M. (2015). Children's experiences of corporal punishment: A qualitative study in an urban township of South Africa. Child Abuse \& Neglect, 48, 131-139. https://doi.org/ 10.1016/j.chiabu.2015.04.022.

Derogatis, L., Lipman, R., \& Covi, L. (1973). SCL-90: An outpatient psychiatric rating scale: Preliminary report. Psychopharmacology Bulletin, 9, 13-27.

Ferguson, C. J. (2013). Spanking, corporal punishment and negative long-term outcomes: A meta-analytic review of longitudinal studies. Clinical Psychology Review, 33(1), 196-208. https://doi.org/10. 1016/j.cpr.2012.11.002.

Finne, L. B., Christensen, J. O., \& Knardahl, S. (2014). Psychological and social work factors as predictors of mental distress: A prospective study. PLoS One, 9(7), e102514. https://doi.org/10.1371/journal. pone. 0102514

Finne, L. B., Christensen, J. O., \& Knardahl, S. (2016). Psychological and social work factors as predictors of mental distress and positive affect: A prospective, multilevel study. PLoS One, 11(3), e0152220. https://doi.org/10.1371/journal.pone.0152220.

Finnish Law (1983). Article 1.3 of the child custody and right of access act. Retrieved from https://www.finlex.fi/fi/laki/ajantasa/1983/ 19830361.

Gershoff, E. T. (2002). Corporal punishment by parents and associated child behaviors and experiences: A meta-analytic and theoretical review. Psychological Bulletin, 128(4), 539. https://doi.org/10. 1016/j.cpr.2012.11.002.

Gershoff, E. T. (2013). Spanking and child development: We know enough now to stop hitting our children. Child Development Perspectives, 7(3), 133-137. https://doi.org/10.1111/cdep.12038.

Hankin, B. L., Kassel, J. D., \& Abela, J. R. (2005). Adult attachment dimensions and specificity of emotional distress symptoms: Prospective investigations of cognitive risk and interpersonal stress generation as mediating mechanisms. Personality \& Social Psychology Bulletin, 31(1), 136-151. https://doi.org/10.1177/ 0146167204271324.

Harper, F. W. K., Brown, A. M., Arias, I., \& Brody, G. (2006). Corporal punishment and kids: How do parent support and gender influence child adjustment? Journal of Family Violence, 21(3), 197-207. https://doi.org/10.1007/s10896-006-9018-2.

Janson, S., Långberg, B., \& Svensson, B. (2011). A 30-year ban on physical punishment of children. In J. E. Durrant \& A. B. Smith (Eds.), Global pathways to abolishing physical punishment:
Realizing children's rights (pp. 241-255). New York: Routledge. https://doi.org/10.4324/9780203839683-27.

Kemme, S., Hanslmaier, M., \& Pfeiffer, C. (2014). Experience of parental corporal punishment in childhood and adolescence and its effect on punitiveness. Journal of Family Violence, 29(2), 129-142. https:// doi.org/10.1007/s10896-013-9564-3.

Kiviniemi, A. A. I., Wasz-Höckert, O., Seitamo, L. K., Joskitt, L. O., Heikkinen, H. P., Moilanen, I. K., \& Ebeling, H. E. (2011). The association between parental images and satisfaction in intimate relationships in a northern Finland sample. International Journal of Circumpolar Health, 70, 2. https://doi.org/10.3402/ijch.v70i2. 17805.

Kiviniemi, A. A. I., Heikkinen, H. P., Koivumaa-Honkanen, H. J., WaszHöckert, O., Seitamo, L. K., Moilanen, I. K., \& Ebeling, H. E. (2016). Gender differences in parental images and intimate relationships: A northern Finland sample. Journal of Child and Family Studies, 25(10), 2972-2986. https://doi.org/10.1007/s10826-016$0457-\mathrm{y}$.

Leiman, M. (2012). Dialogical sequence analysis in studying psychotherapeutic discourse. International Journal for Dialogical Science, 6(1), 123-147.

Mallers, M. H., Charles, S. T., Neupert, S. D., \& Almeida, D. M. (2010). Perceptions of childhood relationships with mother and father: Daily emotional and stressor experiences in adulthood. Developmental Psychology, 46(6), 1651-1661. https://doi.org/10.1037/a0021020.

Mikulincer, M., \& Shaver, P. R. (2007). Attachment in adulthood Structure, dynamics, and change. New York Guilford Press.

Oshio, T., Umeda, M., \& Kawakami, N. (2013). Childhood adversity and adulthood subjective well-being Evidence from Japan. Journal of Happiness Studies, 14(3), 843-860. https://doi.org/10.1007/s10902012-9358-y.

Osterman, K., Bjorkqvist, K., \& Wahlbeck, K. (2014). Twenty-eight years after the complete ban on the physical punishment of children in Finland: Trends and psychosocial concomitants. Aggressive Behavior, 40(6), 568-581. https://doi.org/10.1002/ab.21537.

Osterman, K., Bjorkqvist, K., \& Wahlbeck, K. (2018). A decrease in victimization from physical punishment in Finland in 1934-2014: An evidence of an emerging culture of nonviolent parenting. Ejmo, 2(4), 221-230. https://doi.org/10.14744/ejmo.2018.0027.

Peltoniemi, T. (1983). Child abuse and physical punishment of children in Finland. Child Abuse \& Neglect, 7(1), 33-36.

Perris, C., Jacobsson, L., Linndström, H., Knorring, L. v., \& Perris, H. (1980). Development of a new inventory for assessing memories of parental rearing behaviour. Acta Psychiatrica Scandinavica, 61(4), 265-274. https://doi.org/10.1111/j.1600-0447.1980.tb00581.x.

Prinzie, P., Stams, G. J. J., Deković, M., Reijntjes, A. H., \& Belsky, J. (2009). The relations between parents' big five personality factors and parenting: A metaanalytic review. Journal of Personality and Social Psychology, 97(2), 351. https://doi.org/10.1037/a0015823.

Pulkkinen, L. (1994). Millaista lastenkasvatusta nykytutkimus suosittelee. [What kind of children growing the present study recommends]. In J. Virkki (Ed.), Ydinperheestä yksilöllistyviin perheisiin. [From the nuclear family to the individualistic families] (pp. 26-45). Juva: WSOY.

Pulkkinen, L. (1996). Kasvaminen aikuiseksi. [Growing up to adulthood]. In L. Pulkkinen (Ed.), Lapsesta aikuiseksi. [From childhood to adulthood]. Jyväskylä. Finland Atena.

Pulkkinen, L. (2002). Mukavaa yhdessä: Sosiaalinen alkupääoma ja lapsen sosiaalinen kehitys. [Nice together: Initial social capital and the child's socioemotional development]. Jyväskylä. Finland PS-kustannus.

Rauhala, U. (1966). The social stratification of Finnish society. Helsinki University of Helsinki, institute of social policy. Retrieved from https://oula.finna.fi/Record/oula.548705.

Sandanger, I., Moum, T., Ingebrigtsen, G., Dalgard, O. S., Sørensen, T., \& Bruusgaard, D. (1998). Concordance between symptom screening 
and diagnostic procedure: The Hopkins symptom checklist-25 and the composite international diagnostic interview I. Social Psychiatry and Psychiatric Epidemiology, 33(7), 345-354. https://doi.org/10. 1007/s001270050064.

Sariola, H. (2014). Herra koivuniemi pantu viralta - 30 vuotta ruumiillisen kurittamisen kieltämisestä. [Children are no longer hit with birch branches: 30 years after the prohibition of physical punishment of children in Finland]. Helsinki, Finland.

Saunders, B. J. (2019). In Bryce I., Robinson Y. and Petherick W. (Eds.), Chapter 12 - Physical 'discipline', child abuse, and children's rights. Academic press. https://doi.org/10.1016/B978-0-12-815344-4. 00012-X.

Seitamo, L., \& Wasz-Höckert, O. (1981). Early mother-child relationship in the light of infant cry studies. Acta Paedopsychiatrica International Journal of Child \& Adolescent Psychiatry, 47(4), 215-222.

Seitamo, L., Lammi, A., \& Wasz-Höckert, O. (1979). Mother's response to her newborn baby. In L. Carenza \& L. Zichella (Eds.), Emotion and reproduction (Vol. Vol 20, B ed., pp. 1177-1183). London: Academic press.

Shaw, B. A., Krause, N., Chatters, L. M., Connell, C. M., \& IngersollDayton, B. (2004). Emotional support from parents early in life, aging, and health. Psychology and Aging, 19(1), 4-12. https://doi. org/10.1037/0882-7974.19.1.4.

Stetsenko, A., \& Arievitch, I. M. (2004). The self in cultural-historical activity theory reclaiming the unity of social and individual dimensions of human development. Theory \& Psychology, 14(4), 475503. https://doi.org/10.1177/0959354304044921.

Tazuke, K. (2017). Attachment styles and parental images: An exploratory examination using the twenty-statement test. The Japanese Journal of Personality, 25(3), 191-205 Retrieved from https:// www.jstage.jst.go.jp/article/personality/25/3/25_191/ pdf.
Veijola, J., Jokelainen, J., Läksy, K., Kantojärvi, L., Kokkonen, P., Järvelin, M., \& Joukamaa, M. (2003). The Hopkins symptom checklist-25 in screening DSMIII-R axis-I disorders. Nordic Journal of Psychiatry, 57(2), 119-123. https://doi.org/10.1080/ 08039480310000941 .

Vittrup, B., \& Holden, G. W. (2010). Children's assessments of corporal punishment and other disciplinary practices: The role of age, race, SES, and exposure to spanking. Journal of Applied Developmental Psychology, 31(3), 211-220. https://doi.org/10.1016/j.appdev.2009. 11.003 .

Waters, E., Weinfield, N. S., \& Hamilton, C. E. (2000). The stability of attachment security from infancy to adolescence and early adulthood: General discussion. Child Development, 71(3), 703-706.

Widom, C. S., Czaja, S. J., Kozakowski, S. S., \& Chauhan, P. (2018). Does adult attachment style mediate the relationship between childhood maltreatment and mental and physical health outcomes? https://doi.org/10.1016/j.chiabu.2017.05.002.

Winokur, A., Winokur, D. F., Rickels, K., \& Cox, D. S. (1984). Symptoms of emotional distress in a family planning service: Stability over a four-week period. The British Journal of Psychiatry the Journal of Mental Science, 144, 395-399. https:// doi.org/10.1192/bjp.144.4.395.

Yaffe, Y., \& Burg, D. (2014). Corporal punishment as a parental practice and anxiety in pre-adolescent children. Journal of Social Science Studies, 1(2), 13-31. https://doi.org/10.5296/jsss.v1i2.5099.

Zhang, F., \& Labouvie-Vief, G. (2004). Stability and fluctuation in adult attachment style over a 6-year period. Attachment \& Human Development, 6(4), 419-437. https://doi.org/10.1080/ 1461673042000303127 .

Publisher's Note Springer Nature remains neutral with regard to jurisdictional claims in published maps and institutional affiliations. 